\title{
Tropospheric Range-Error Corrections for the Global Positioning System
}

\author{
Edward E. Altshuler, Life Fellow, IEEE
}

\begin{abstract}
The global positioning system (GPS) is a highly accurate navigation system that has a broad spectrum of military, civilian, and commercial applications. It uses a triangulation scheme based on the time delays of signals from the satellites to the user; these time delays are then equated to distances. However, as the timing signal passes through the earth's atmosphere it undergoes an additional time delay due to the index of refraction. The time delay produced by the troposphere approaches a value corresponding to a range error of about $25 \mathrm{~m}$ for an elevation angle of $5^{\circ}$ and decreases with increasing elevation angle to less than a few meters at zenith. It has been shown that there is a good correlation between the range error and the surface index of refraction. Worldwide statistics of surface refractivity have been analyzed and shown to be correlated with site latitude, height above sea level, and time of year. Regression lines for range-error corrections based on these parameters are derived. Range-error accuracies vary from about $8 \%$ down to $3.7 \%$ of the total range error, depending on the amount of information that is available.
\end{abstract}

Index Terms-Global positioning system.

\section{INTRODUCTION}

$\mathbf{T}$ HE global positioning system (GPS) is a highly accurate navigation system that provides timing, velocity, and positioning information. It is a triservice system that evolved from four previous satellite systems: transit, a U.S. Navy system developed by Johns Hopkins Applied Research Lab; Timation, developed at the Naval Research Lab; Project 621B, an Air Force Study Program; and the Defense Navigation Satellite System. By 1972, the best features of these systems coalesced into the system previously known as NAVSTAR global positioning system, now known as simply GPS. It has a broad spectrum of military, civilian, and commercial users. It consists of 21 satellites plus three in-orbit spares in six orbital planes, each in a 10900 nautical mile circular orbit with a $12 \mathrm{~h}$ period. It broadcasts continually at frequencies of 1227.6 and $1575.2 \mathrm{MHz}$. It uses a triangulation scheme based on the time delays of signals from the satellites to the user; the time delays are then equated to distances. However, as the timing signal passes through the earth's atmosphere it undergoes an additional time delay due to the finite index of refraction of the atmosphere. The larger part of this delay is due to the ionosphere; the other part is due to the troposphere. The additional ionospheric delay can produce a range error of over $30 \mathrm{~m}$. However, because the ionosphere is dispersive, the index of refraction has a strong frequency dependence.

Manuscript received June 16, 1997; revised November 4, 1997.

The author is with the Air Force Research Laboratory, Electromagnetics and Reliability Directorate, Hanscom AFB, MA 01731 USA.

Publisher Item Identifier S 0018-926X(98)03371-7.
By operating the system at two frequencies, it is possible to accurately correct for the ionospheric range error.

The additional time delay produced by the troposphere is not frequency dependent, so the two-frequency approach does not help. This delay approaches a value corresponding to a range error of about $25 \mathrm{~m}$ for an elevation angle of $5^{\circ}$ and decreases with increasing elevation angle to less than a few meters at zenith. In order to determine this additional delay, the index of refraction along the ray path must be known; in general, this is not possible. A number of models of the index of refraction as a function of altitude have been used for estimating the tropospheric range error. Based on these results it was shown that there is a good correlation between the range error and the surface index of refraction-a parameter that is generally available. In 1971, Altshuler [1] computed a set of range-error corrections as a function of the surface refractivity, the height of the user above sea level, and the elevation angle to the satellite. The equations used for these calculations could not be easily evaluated in real time with state of the art computers, so, in 1974, Altshuler and Kalaghan [2] converted the previous equations into a set of polynomialtype equations that were more computer friendly. In addition, they also examined world-wide surface refractivity statistics and showed that the refractivity is correlated with the site latitude, height above sea level, and time of year. In this paper, we present an algorithm for estimating the tropospheric range error from the user height above sea level, latitude, day of year, and elevation angle to the satellite from the GPS receiver. A sensitivity analysis of this algorithm is also presented.

\section{REFRACTIVITY MODELS}

The index of refraction $n$ of the troposphere is only about 1.0003 at the earth's surface, so it is usually represented by a refractivity $N$ where $N=(n-1) \times 10^{6}$. Numerous refractivity $(N)$ profiles have been obtained over the years from samples measured directly with a refractometer or calculated from measurements of temperature, pressure, and absolute humidity. A number of models have been generated from these data for the purpose of correcting for tropospheric effects on propagation. Historically, the earth's radius model formulated by Schelleng et al. [3] was first used for line-of-sight communications problems. It was shown that by assuming an earth having a radius of about $4 / 3$ times that of the actual earth, radio rays could be drawn as straight lines. The $4 / 3$ earth model works well for propagation paths at low altitudes, where ray paths are within about $2 \mathrm{~km}$ of the earth' s surface, but not for those at higher altitudes. From an examination of many years of $\mathrm{N}$ - 
profile data for various climates it appears that $N$ decreases linearly from the surface to an altitude of about $1 \mathrm{~km}$ above the earth's surface and then exponentially to an altitude of about $9 \mathrm{~km}$ at which the variation in refractivity is a minimum, with a range of about only $8 \mathrm{~N}$ units and an average value of 104.8 $\mathrm{N}$ units [4]. The rocket panel data [5], the ARDC model atmosphere [6], and work by Dubin [7] showed that above $9 \mathrm{~km}$, refractivity again decreases exponentially. These data were used in formulating the model known as the CRPL reference atmosphere 1958 [4], which includes the following expressions for refractivity for three ranges of altitude:

$$
N(h)=N_{s}\left(h-h_{s}\right) \Delta N, \quad h_{s}<h<h_{s}+1 \mathrm{~km}
$$

where

$$
\begin{aligned}
\Delta N & =-7.32 \exp (0.005577) N_{s} \\
N(h) & =N_{1} \exp \left[-c\left(h-h_{s}-1\right)\right], \quad h_{s+1}<h<9 \mathrm{~km}
\end{aligned}
$$

where

$$
c=\frac{1}{8-h_{s}} \ln \frac{N_{1}}{105}
$$

and

$$
N(h)=105 \exp [-0 . \quad 1424(h-9)], \quad h>9 \mathrm{~km}
$$

where

$N(h)$ refractivity at altitude $h$ above sea level;

$N_{S} \quad$ surface refractivity;

$N_{1}$ refractivity at altitude $1 \mathrm{~km}$ above the surface;

$h_{S}$ height of surface above sea level.

To simplify these expressions, the following single exponential (referred to as the CRPL exponential reference atmosphere 1958) was generated:

$$
N(h)=N_{S} \exp \left[-c_{e}\left(h-h_{S}\right)\right]
$$

where

$$
c_{e}=\ln \frac{N_{S}}{N_{S}+\Delta N} .
$$

Although this model is in good agreement with refractivity data below about $8 \mathrm{~km}$, the values it gives at higher altitudes are too low. For example, at an altitude of $9 \mathrm{~km}$ the average refractivity is about 105 , with minimum and maximum values of 100 and 108, respectively; but, at this altitude, the exponential reference atmosphere gives a value of only 85 for $N_{S}=313$ (average surface refractivity in the United States). This model is, therefore, not expected to be very useful for range-error calculations. Hopfield [8] noted that if the refractivity as a function of height is represented by an exponential, it is not integrable in closed form, whereas if it has the form

$$
N=k\left(h_{0 \mu}-h\right)^{\mu}, \quad h \leq h_{0}
$$

it is integrable. She showed that representing the dry and wet terms of refractivity by quartic equations $(\mu=4)$ gave good agreement with range error and doppler data [9].

A number of other models of refractivity have been proposed and are summarized in Parkinson and Spilker [10]. They are, for the most part, variations of those mentioned above and will not be discussed. Probably the best source of refractivity data is the CRPL standard atmospheric radio refractive index sample [11]. It consists of a sample of $77 \mathrm{~N}$ profiles selected from thirteen radiosonde stations representative of the major geographic and climatic types of the world.

\section{FORMULATION OF SIMPLIFIED EXPRESSION FOR RANGE ERROR}

Range errors were calculated for each of the 77 profiles as a function of elevation angle using ray-tracing and leastsquare regression lines of the form $\Delta R_{e}=a+b N S$ and were obtained as a function of angle. For elevation angles above $5^{\circ}$, range errors calculated from the CRPL reference atmosphere 1958 were found to be in good agreement with those obtained from this regression line [12]. Millman [13] used the CRPL reference atmosphere 1958 and a ray-tracing program to generate extensive curves for range error as a function of elevation angle, surface refractivity, and height. By selecting a model consisting of stratified layers only $50 \mathrm{~m}$ thick from ground level to an altitude of $30 \mathrm{~km}$ and taking into account refractive bending, he was able to compute very accurate range errors. Our objective is to generate a simple expression that will provide range errors in close agreement with those computed by Millman [13] for elevation angles of $5^{\circ}$ and above. Bean and Dutton [4] had shown that the total range error based on the CRPL standard sample is of the form

$$
\Delta R_{e}=\csc \theta_{0}\left(1.4588+0.0029611 N_{s}\right)
$$

where

$\begin{aligned} \Delta R_{e} & \text { range error in meters; } \\ \theta_{0} & \text { elevation angle; } \\ N_{s} & \text { surface refractivity. }\end{aligned}$

A comparison of range errors obtained from (1) with those computed by Millman [13] (see Fig. 1) shows that the differences increase approximately exponentially with decreasing elevation angle for constant surface refractivity. Plotted as a function of refractivity for constant elevation angle (Fig. 2) the differences are shown to be quadratic in form. Hence, subtracting a term of the form

$$
\Delta\left(\theta, N_{s}\right)=\Delta\left[c_{1} \theta^{c_{2}}, c_{3}\left(N_{s}-c_{4}\right)^{2}+c_{5}\right]
$$

from (1) provides a best fit to the curve. As shown in Appendix A

$$
\Delta\left(\theta, N_{s}\right)=\left[0.001786\left(N_{s}-360\right)^{2}+89.6\right] \theta^{-2.30}
$$

Therefore

$$
\begin{aligned}
\Delta R_{e o}= & \frac{1.4588+0.002961 N_{s}}{\sin \theta} \\
& -\left[0.001786\left(N_{s}-360\right)^{2}+89.6\right] \theta^{-.230}
\end{aligned}
$$

where

$\Delta R_{\text {eo }}$ range error in meters;

$\theta$ elevation angle in degrees;

$N_{s} \quad$ refractivity in $N$ units at the surface. 


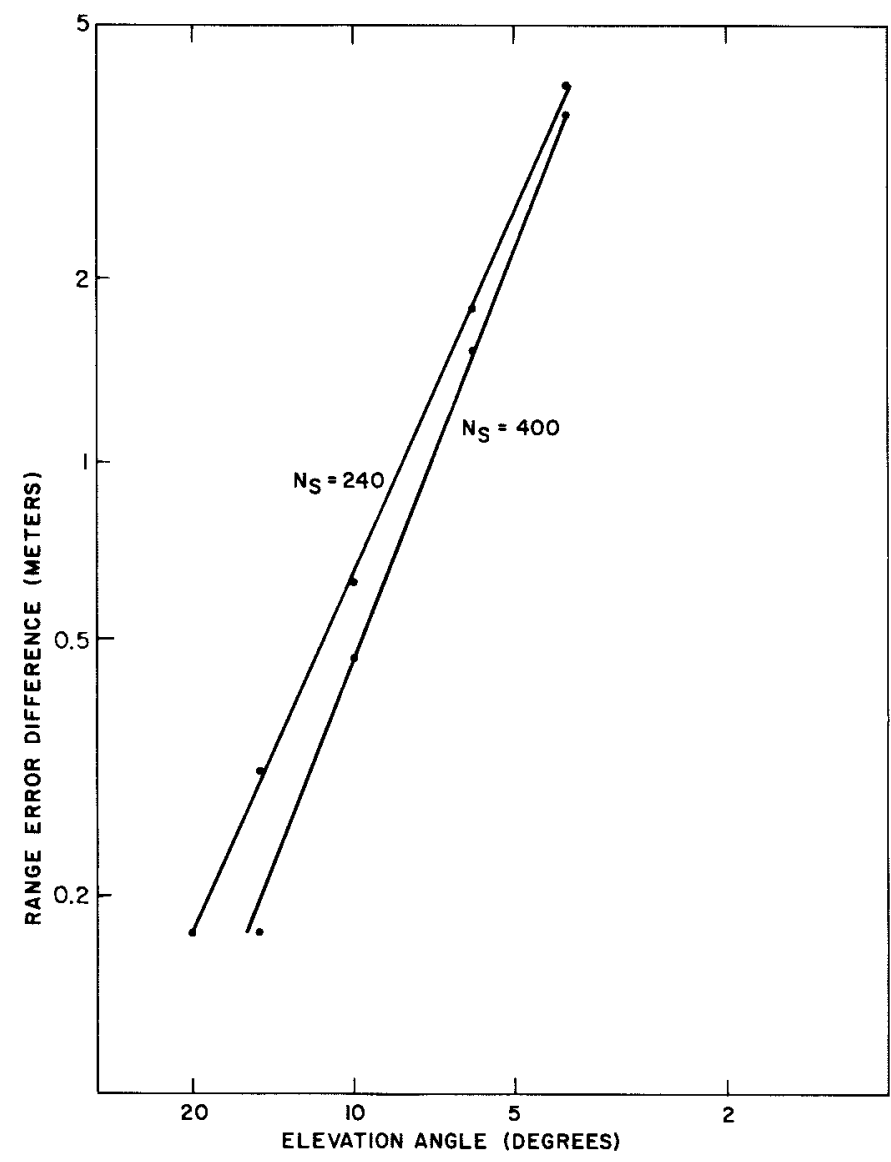

Fig. 1. Differences between approximate and more accurate expressions for range error as a function of elevation angle for constant surface refractivity.

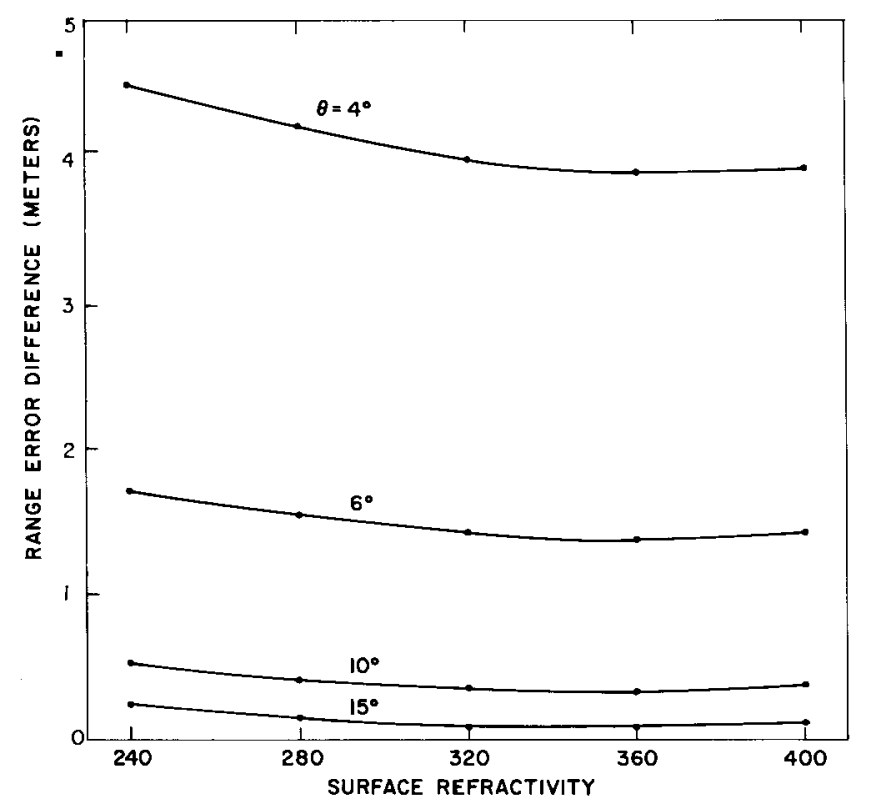

Fig. 2. Differences between approximate and more accurate expressions for range error as a function of surface refractivity for constant elevation angle.

Equation (3) yields range errors from the earth's surface through the total troposphere that are within $0.2 \mathrm{~m}$ of those computed by Millman [13]. The next step is to obtain an expression for range error for an aircraft to the satellite. Range

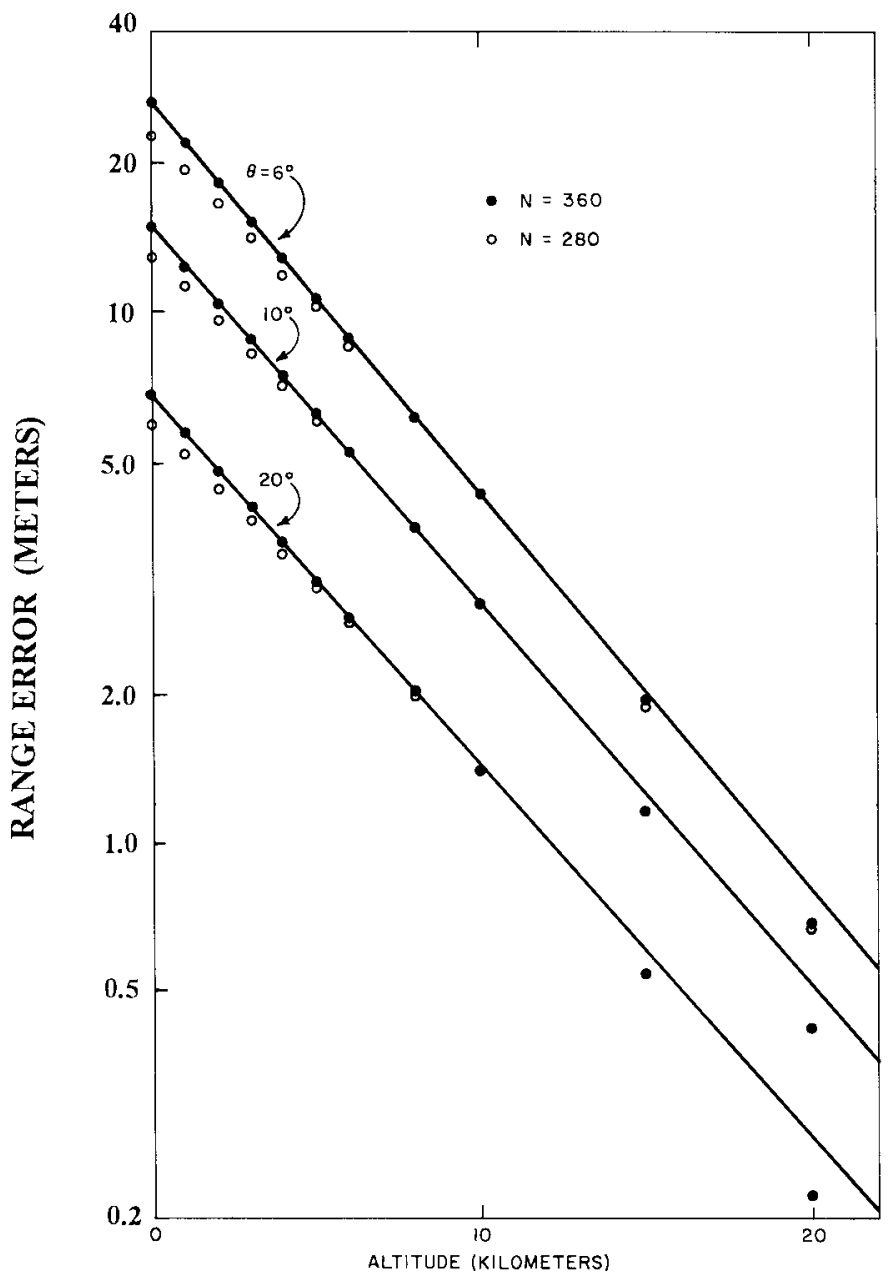

Fig. 3. Range error as a function of altitude for selected angles and surface refractivities.

errors for a path from sea level to an aircraft at altitude $h$ have been computed by Millman [14]. From these results, it is possible to estimate the range error for the path between an aircraft and a satellite. For example, if the total range error from sea level to a satellite is $\Delta R_{e 0}$ and the range error from sea level to an aircraft at altitude $h$ is $\Delta R_{e}^{\prime}$, then the range error $\Delta R_{e h}$ for an aircraft at altitude $h$ to the satellite is approximately $\Delta R_{e h}=\Delta R_{e 0}-\Delta R_{e}^{\prime}$. From Fig. 3 where Millman's [14] range errors are plotted as a function of altitude for several elevation angles and surface refractivities of $N=280$ and $N=360$, it can be seen that the height dependence of range error is almost exponential at low altitudes but falls off more rapidly at higher altitudes. In Appendix B it is shown that the range error from an aircraft at altitude $h$ through the total troposphere to a satellite can be approximated by

$$
\begin{aligned}
\Delta R_{e h}= & \Delta R_{e o} \exp \\
& -\left[\left(0.0002 N_{S}+0.070\right) h+\left(\frac{0.83}{N_{S}}-0.0017\right) h^{2}\right] .
\end{aligned}
$$

Equation (4) yields range errors that agree with Millman's values to within $\pm 0.2 \mathrm{~m}$. It has now been shown that range 
errors in excellent agreement with those obtained based on the CRPL reference atmosphere 1958 can be computed quite easily from (4) for elevation angles of $5^{\circ}$ and above. It has been assumed that the surface refractivity is known. The accepted expression for the calculation of refractivity from temperature, pressure, and water vapor pressure is

$$
N(h)=77.6 P(h) / T(h)+3.73 \times 10^{-5} e(h) /[T(h)]^{2}
$$

where

$P(h)$ pressure in millibars at altitude $h$;

$T(h)$ temperature in degrees Kelvin at altitude $h$;

$e(h)$ water vapor pressure in millibars at altitude $h$.

$P(h)=$ pressure in millibars at altitude $h$,

$T(h)=$ temperature in degrees Kelvin at altitude $h$,

$e(h)=$ water vapor pressure in millibars at altitude $h$.

For an aircraft at altitude $h$, the refractivity is related to the surface refractivity by

$$
N(h)=N_{s} \exp (-h / H)
$$

where $H$ is a scale height of about $7 \mathrm{~km}$ [4].

Therefore

$$
N(h)=N_{s} \exp (-.143 h)
$$

where $h$ is the height above sea level in kilometers.

If the surface refractivity is not known, it must be estimated. A statistical analysis of our surface refractivity data showed that the average global surface refractivity is $324.8 \mathrm{~N}$-units and that the standard deviation of this sample is $30.1 \mathrm{~N}$-units. A further analysis of the data showed that $N_{s}$ is correlated with site latitude and day of year. The following regression line of $N_{s}$ as a function of these parameters can therefore be derived:

$$
\begin{gathered}
N_{s}=369.0-|L|\left[.9244-.1936 \sin ^{2}\left(\pi d_{\mathrm{mod}} / 365\right)\right. \\
\left.+.0596 \cos ^{2}\left(\pi d_{\mathrm{mod}} / 365\right)\right]
\end{gathered}
$$

where

$N_{s} \quad$ surface refractivity;

$d$ day of year;

$L \quad$ latitude

$$
\begin{aligned}
& \text { if } L \geq 0 \text {, then } d_{\mathrm{mod}}=d \\
& \text { if } L<0 \text {, then } d_{\mathrm{mod}}=\bmod ((d=182), 365) \text {. }
\end{aligned}
$$

This expression describes the worldwide variation of $N_{s}$ and has a standard error of $17.0 \mathrm{~N}$-units, approximately $5 \%$ of the mean $N_{s}$ value.

For illustration, monthly surface refractivities are tabulated in Table I. for the northern hemisphere. It is seen that the surface refractivity ranges from a low of about 280 near the pole to $369 \mathrm{~N}$-units at the equator. The corresponding range errors through the troposphere for an elevation angle of $5^{\circ}$ range from 23.8 to $27.1 \mathrm{~m}$. Thus, there is a difference of over $3 \mathrm{~m}$, depending on the latitude of the GPS receiver. Typical range errors as a function of elevation angles, height of the receiver above sea level, elevation angle to the satellite, and surface refractivity are shown in Table II. Note the decrease in range error with increasing height and elevation angle.

\begin{tabular}{|c|c|c|c|c|c|}
\hline \multicolumn{6}{|c|}{$N_{s}=\mathbf{2 8 0}$} \\
\hline $\mathrm{h} / \theta$ & 5 & 10 & 20 & 60 & 90 \\
\hline 0 & 23.78 & 12.70 & 6.59 & 2.63 & 2.29 \\
\hline 5 & 12.34 & 6.58 & 3.42 & 1.37 & 1.19 \\
\hline 10 & 6.08 & 3.24 & 1.68 & 0.67 & 0.58 \\
\hline 20 & 1.27 & 0.68 & 0.35 & 0.14 & 0.12 \\
\hline \multicolumn{6}{|c|}{$N_{s}=320$} \\
\hline $\mathrm{h} / \theta$ & 5 & 10 & 20 & 60 & 90 \\
\hline 0 & 25.35 & 13.40 & 6.95 & 2.77 & 2.40 \\
\hline 5 & 12.77 & 6.75 & 3.50 & 1.39 & 1.21 \\
\hline 10 & 6.21 & 3.28 & 1.70 & 0.68 & 0.59 \\
\hline 20 & 1.34 & 0.71 & 0.37 & 0.14 & 0.12 \\
\hline \multicolumn{6}{|c|}{$N_{s}=360$} \\
\hline $\mathrm{h} / \theta$ & 5 & 10 & 20 & 60 & 90 \\
\hline 0 & 26.78 & 14.10 & 7.30 & 2.91 & 2.52 \\
\hline 5 & 13.06 & 6.88 & 3.56 & 1.42 & 1.23 \\
\hline 10 & 6.24 & 3.29 & 1.70 & 0.68 & 0.59 \\
\hline 20 & 1.35 & 0.71 & 0.37 & 0.15 & 0.13 \\
\hline
\end{tabular}

TABLE I

Surface Refractivities as a Function of Latitude and Month

\begin{tabular}{ccccccccccc}
\hline MUL & $\mathbf{0}$ & $\mathbf{1 0}$ & $\mathbf{2 0}$ & $\mathbf{3 0}$ & $\mathbf{4 0}$ & $\mathbf{5 0}$ & $\mathbf{6 0}$ & $\mathbf{7 0}$ & $\mathbf{8 0}$ & $\mathbf{9 0}$ \\
& & & & & & & & & & \\
JAN & 369 & 359 & 349 & 340 & 330 & 320 & 310 & 300 & 291 & 281 \\
FEB & 369 & 360 & 350 & 341 & 331 & $\mathbf{3 2 2}$ & 312 & 303 & 293 & 284 \\
MAR & 369 & 360 & 351 & 342 & 333 & 324 & 315 & 306 & 297 & 288 \\
APR & 369 & 361 & 352 & 344 & 336 & 328 & 319 & 311 & 303 & 294 \\
MAY & 369 & 361 & 354 & 346 & 338 & 330 & 323 & 315 & 307 & 300 \\
JUN & 369 & 362 & 354 & 347 & 340 & 332 & 325 & 318 & 310 & 303 \\
JUL & 369 & 362 & 354 & 347 & 340 & 332 & 325 & 318 & 310 & 303 \\
AUG & 369 & 361 & 354 & 346 & 338 & 331 & 323 & 315 & 308 & 300 \\
SEP & 369 & 361 & 353 & 344 & 336 & 328 & 320 & 311 & 303 & 295 \\
OCT & 369 & 360 & 351 & 342 & 334 & 325 & 316 & 307 & 298 & 290 \\
NOV & 369 & 360 & 350 & 341 & 331 & 322 & 312 & 303 & 294 & 284 \\
DEC & 369 & 359 & 350 & 340 & 330 & 320 & 310 & 300 & 291 & 281 \\
& & & & & & & & & &
\end{tabular}

TABLE II

Range-Error CORRections as a Function of Elevation Angle, Height Above Sea Level, and Surface Refractivity

\section{DISCUSSION OF ERRORS}

It is extremely difficult to determine the accuracy with which tropospheric range error can be estimated since it is not practicable to measure range error directly. Although range error can be accurately calculated by means of ray tracing techniques, if the refractivity along the path is known, it is not always possible to ascertain atmospheric refractivity since it is variously affected by winds, clouds, and precipitation. In addition, the assumption that the atmosphere is horizontally stratified is not always valid. It is particularly difficult to accurately measure refractivity at the higher altitudes. There is no uniformity of sensors used in radiosondes; although temperature and pressure sensors generally show fair agreement, humidity sensors are erratic [4]. Refractometers are more capable of accurately measuring refractivities, but they are relatively expensive and complex to operate. Also it should be emphasized that the correlations of range error were with surface refractivity while the GPS altitude corresponds to height above sea level. Fortunately, there are not too many locations for which this difference is significant. With these 
TABLE III

UNCERTAINTY IN RANGE ERROR DUE TO UNCERTAINTY IN SURFACE REFRACTIVITY (m/N-UNIT)

$\begin{array}{cccccccccc}\theta \backslash \mathbf{N}, & \mathbf{2 4 0} & \mathbf{2 6 0} & \mathbf{2 8 0} & \mathbf{3 0 0} & \mathbf{3 2 0} & \mathbf{3 4 0} & \mathbf{3 6 0} & \mathbf{3 8 0} & \mathbf{4 0 0} \\ \mathbf{4} & 0.067 & 0.057 & 0.054 & 0.051 & 0.048 & 0.045 & 0.042 & 0.040 & 0.037 \\ \mathbf{5} & 0.044 & 0.043 & 0.041 & 0.039 & 0.037 & 0.036 & 0.034 & 0.032 & 0.030 \\ \mathbf{6} & 0.035 & 0.034 & 0.033 & 0.032 & 0.031 & 0.030 & 0.028 & 0.027 & 0.026 \\ \mathbf{7} & 0.029 & 0.028 & 0.027 & 0.027 & 0.026 & 0.025 & 0.024 & 0.0230 & 0.023 \\ \mathbf{8} & 0.025 & 0.024 & 0.024 & 0.023 & 0.023 & 0.022 & 0.021 & 0.021 & 0.020 \\ \mathbf{9} & 0.022 & 0.021 & 0.021 & 0.020 & 0.020 & 0.020 & 0.019 & 0.019 & 0.018 \\ \mathbf{1 0} & 0.019 & 0.019 & 0.019 & 0.018 & 0.018 & 0.017 & 0.017 & 0.017 & 0.016 \\ \mathbf{1 2} & 0.016 & 0.016 & 0.015 & 0.015 & 0.015 & 0.015 & 0.014 & 0.014 & 0.014 \\ \mathbf{1 4} & 0.013 & 0.013 & 0.013 & 0.013 & 0.012 & 0.012 & 0.012 & 0.012 & 0.012 \\ \mathbf{1 6} & 0.012 & 0.011 & 0.011 & 0.011 & 0.011 & 0.011 & 0.011 & 0.011 & 0.010 \\ \mathbf{1 8} & 0.010 & 0.010 & 0.010 & 0.010 & 0.010 & 0.010 & 0.009 & 0.009 & 0.009 \\ \mathbf{2 0} & 0.009 & 0.009 & 0.009 & 0.009 & 0.009 & 0.009 & 0.009 & 0.009 & 0.009 \\ \mathbf{2 5} & 0.007 & 0.007 & 0.007 & 0.007 & 0.007 & 0.007 & 0.007 & 0.007 & 0.007 \\ \mathbf{3 0} & 0.006 & 0.006 & 0.006 & 0.006 & 0.006 & 0.006 & 0.006 & 0.006 & 0.006 \\ \mathbf{4 0} & 0.005 & 0.005 & 0.005 & 0.005 & 0.005 & 0.005 & 0.005 & 0.005 & 0.005 \\ \mathbf{5 0} & 0.004 & 0.004 & 0.004 & 0.004 & 0.004 & 0.004 & 0.004 & 0.004 & 0.004 \\ \mathbf{6 0} & 0.003 & 0.003 & 0.003 & 0.003 & 0.003 & 0.003 & 0.003 & 0.003 & 0.003 \\ \mathbf{7 0} & 0.003 & 0.003 & 0.003 & 0.003 & 0.003 & 0.003 & 0.003 & 0.003 & 0.003 \\ \mathbf{8 0} & 0.003 & 0.003 & 0.003 & 0.003 & 0.003 & 0.003 & 0.003 & 0.003 & 0.003 \\ \mathbf{9 0} & 0.003 & 0.003 & 0.003 & 0.003 & 0.003 & 0.003 & 0.003 & 0.003 & 0.003\end{array}$

limitations in mind, we proceed to examine the range-error corrections.

The standard errors in range error, calculated from the standard errors in surface refractivity by using (4), are listed in Table III as a function of surface refractivity $N_{s}$ and elevation angle $\theta$. These tabulations represent only the uncertainties that are due to the statistical variation in surface refractivity. Even when the surface refractivity is known, the model has an inherent error, which must also be included. Unfortunately, the accuracy with which range error can be corrected on the basis of the CRPL reference atmosphere 1958 is extremely difficult to determine. Norton [11] has calculated range errors for the CRPL standard sample and plotted the standard deviation of the normalized range error $\Delta R_{e} / R_{e}$ for cases for which the surface refractivity is both known and unknown. If it is assumed that the standard deviation of the range error for the CRPL reference atmosphere 1958 is the same as for the CRPL standard sample, then the accuracy of the rangeerror correction for a horizontally stratified atmosphere can be estimated. Errors due to atmospheric anomalies such as a nonstratified atmosphere, clouds, and precipitation must also be taken into account; these are estimated to be about $2 \%$ of the total range error.

The standard errors of range-error corrections are listed in Table IV as a function of elevation angle and amount of information available. It is seen that if $N_{s}$ is known, the standard error is approximately $3.7 \%$ of the total value of the range-error correction. If $N_{s}$ is not known, but the latitude, height above sea level, and day of year are known, then the standard error increases to slightly more than $6 \%$. If the latitude of the observer is unknown, the standard error is about $7 \%$. If only the global surface refractivity of $324.8 \mathrm{~N}$ units is used, then the standard error increases to about $8 \%$ of the range-error correction.

For the GPS, for the purpose of estimating the surface refractivity, only the day of year and latitude are given. Since the surface refractivity is a function of the height of the
TABLE IV

Standard Deviation of Range-ErRor Corrections as a Function of Information Available

\begin{tabular}{|c|c|c|c|c|c|}
\hline$\theta$ & $\mathbf{A}$ & B & C & D & Avg $\Delta R_{e}$ \\
\hline 5 & 0.90 & 1.56 & 1.80 & 2.06 & 25.54 \\
\hline 6 & 0.79 & 1.33 & 1.53 & 1.74 & 21.70 \\
\hline 7 & 0.70 & 1.16 & 1.32 & 1.50 & 18.84 \\
\hline 8 & 0.62 & 1.02 & 1.17 & 1.32 & 16.64 \\
\hline 9 & 0.57 & 0.91 & 1.04 & 1.18 & 14.90 \\
\hline 10 & 0.51 & 0.82 & 0.94 & 1.06 & 13.47 \\
\hline 12 & 0.43 & 0.69 & 0.78 & 0.88 & 11.34 \\
\hline 14 & 0.37 & 0.59 & 0.67 & 0.76 & 9.81 \\
\hline 16 & 0.33 & 0.52 & 0.59 & 0.66 & 8.63 \\
\hline 18 & 0.29 & 0.46 & 0.52 & 0.59 & 7.71 \\
\hline 20 & 0.26 & 0.42 & 0.48 & 0.53 & 6.98 \\
\hline 25 & 0.21 & 0.34 & 0.38 & 0.43 & 5.67 \\
\hline 30 & 0.18 & 0.28 & 0.32 & 0.37 & 4.82 \\
\hline 40 & 0.13 & 0.21 & 0.24 & 0.27 & 3.75 \\
\hline 50 & 0.11 & 018 & 0.21 & 0.23 & 3.14 \\
\hline 60 & .010 & 0.16 & 0.18 & 0.20 & 2.77 \\
\hline 70 & 0.09 & 015 & 0.16 & 0.19 & 2.56 \\
\hline 80 & 0.09 & 0.14 & 0.16 & 0.18 & 2.44 \\
\hline 90 & 0.09 & 0.14 & 0.16 & 0.18 & 2.41 \\
\hline$\sigma_{\Delta R e} / \Delta R e$ & 0.037 & 0.061 & 0.070 & 0.080 & \\
\hline \multicolumn{6}{|c|}{$\begin{array}{l}\text { A: } N_{s} \text { known } \\
\text { B: } N_{s} \text { unknown; latitude, altitude and day of year } \\
\text { C: } N_{s} \text { unknown; altitude and day of year known } \\
\text { D: No information }\end{array}$} \\
\hline
\end{tabular}

surface above sea level, an error will arise for locations such as Denver, CO, which is approximately $1625 \mathrm{~m}$ above sea level. Equation (8) would estimate the surface refractivities for Denver to be about 330 and $340 \mathrm{~N}$-units for the 15th (winter) and 195th (summer) days of the year; more accurate values are 250 and $267 \mathrm{~N}$-units, respectively. As a result, the corresponding range errors for an elevation angle of $5^{\circ}$ would be overestimated by about $10 \%$ of the total range error. This type of error could be avoided if both longitude and latitude were used, thus making it possible to identify those locations that are significantly above sea level and including them in the algorithm.

\section{CONCLUSIONS}

Tropospheric range-error corrections based on a global average surface refractivity of $324.8 \mathrm{~N}$ units have a standard error of about $8 \%$ of the total refractive range error. Since the range error from the surface to the satellite varies from about $25 \mathrm{~m}$ for an elevation angle of $5^{\circ}$ to about $2 \mathrm{~m}$ for angles close to zenith, standard errors of about $2-0.2 \mathrm{~m}$ would be expected if all systems throughout the world used corrections based on elevation angle only. It has been shown statistically that range-error corrections based on a regression model that is a function of site latitude, height above sea level, day of year, and elevation angle show a standard error of approximately $6 \%$ of the total range error. Thus, a $25 \%$ improvement in the accuracy of the range-error correction can be obtained by simply using information that can readily be obtained for any user location. If the height of the surface at which the user is located is not used, then the error in estimating the surface refractivity for regions that are at a high elevation can produce a significant error in the surface refractivity estimate, 
which will in turn produce a corresponding overestimation of the range error. However the range-error correction can be further improved if the surface refractivity at the user location is known; the standard error of the range-error correction for this case is only about $3.7 \%$ of the total correction.

It must be emphasized that our results are global and applicable for any location. If the user is confined to a region within which the climatology does not vary appreciably from point to point, then more accurate range-error corrections can be derived from refractivity statistics for that region.

\section{APPENDIX A}

\section{CORRECTION OF RANGE ERROR FROM SEA LEVEL}

As seen in Fig. 1, the range-error difference $\Delta$ has an elevation angle dependence that is approximately linear on a $\log -\log$ scale. Therefore, $\Delta$ should have the form

$$
\ln \Delta\left(\theta, N_{s} \text { constant }\right)=\ln c_{1}+c_{2} \ln \theta
$$

or

$$
\Delta\left(\theta, N_{s} \text { constant }\right)=c_{1} \theta^{c_{2}} .
$$

With $N=240$

$$
\begin{aligned}
& \text { for } \theta=6^{\circ}: \ln 1.8=\ln c_{1}+c_{2} \ln 6^{\circ} \\
& \text { for } \theta=10^{\circ}: \ln 0.55-\ln c_{1}+c_{2} \ln 10^{\circ} .
\end{aligned}
$$

Solving for $c_{1}$ and $c_{2}$ yields

$$
\begin{aligned}
& c_{1}=115 \\
& c_{2}=-2.30 .
\end{aligned}
$$

Therefore

$$
\Delta\left(\theta, N_{s}=240\right)=115 \theta^{-2.30} .
$$

In Fig. 2, the range-error difference was seen to have a refractivity dependence that is slightly quadratic with a minimum at about 360 . Therefore, $\Delta\left(N_{s}, \theta\right.$ constant $)$ should have the form

$$
\Delta\left(N_{s}, \theta \text { constant }\right)=c_{3}(360-280)^{2}+c_{4} .
$$

With $\theta=6^{\circ}$

$$
\begin{aligned}
& \text { for } N_{s}=280: 1.62=c_{3}(360-280)^{2}+c_{4} \\
& \text { for } N_{s}=360: 1.43=c_{4} .
\end{aligned}
$$

Therefore

$$
\begin{aligned}
c_{3} & =2.86 \times 10^{-\tilde{5}} \\
\Delta\left(N_{s}, \theta=6^{\circ}\right) & =2.86 \times 10^{-5}\left(N_{s}-360\right)^{2}+4.7 .
\end{aligned}
$$

To combine these results into a single expression noting that $\Delta$ has a stronger $\theta$-dependence than $N$-dependence, let it be required that

$$
\begin{aligned}
c_{5}\left[\Delta\left(N_{s}, \theta=6^{\circ}\right)\right] & =115, \quad \text { for } N=240 \\
c_{5}\left[2.86 \times 10^{-5}(240-360)^{2}+1.43\right] & =115 . \\
c_{5} & =62.5 .
\end{aligned}
$$

Then

$$
\Delta\left(\theta, N_{s}\right)=\left[0.00178\left(N_{s}-360\right)^{2}+89.4\right] \theta^{-2.30} .
$$

\section{APPENDIX B}

\section{CORRECTION OF RANGE ERROR FrOM AN AIRCRAFT}

Range errors plotted versus altitude on semilog paper (Fig. 3) are seen to be almost linear, which indicates an exponential altitude dependence. To compensate for the nonlinearity at the higher altitudes, an additional term is added. The expression for range error as a function of height is then

$$
\ln \Delta R_{e h}=\ln \Delta R_{e 0}+c_{1} h+c_{2} h^{2} .
$$

The term $c_{1}$ is determined from values of $\Delta R_{e h}$ at $h=0$ and $h=2 \mathrm{~km} ; c_{2}$ is determined from values of $R_{e h}$ at $h=0$ and $h=20 \mathrm{~km}$. Thus

$$
\begin{aligned}
& c_{1}=\left[\ln \Delta R_{e 2}-\ln \Delta R_{e 0}\right] / 2 \\
& c_{2}=\left[\ln \Delta R_{e 20}-\ln \Delta R_{e 0}\right] / 400 .
\end{aligned}
$$

These have been computed for $N_{s}=280$ and $N_{s}=360$ at five elevation angles as follows:

$$
\begin{array}{ccccc} 
& \multicolumn{2}{c}{N s=280} & \multicolumn{2}{c}{N s=360} \\
& C 1 & C 2 & C 1 & C 2 \\
6 & -0.130 & -0.0012 & -0.143 & -0.0007 \\
10 & -0.126 & -0.0012 & -0.143 & -0.0006 \\
15 & -0.123 & -0.0014 & -0.141 & -0.0006 \\
20 & -0.122 & -0.0014 & -0.140 & -0.0004 \\
30 & -0.121 & -0.0012 & -0.139 & -0.0009 .
\end{array}
$$

On the basis of the above results, the constants

for $N_{s}=280$ are taken as: $c_{1}=-0.126, c_{2}$

$$
=-0.0013
$$

for $N_{s}=360$ are taken as: $c_{1}=-0.142, c_{2}=-0.0006$.

Since these constants vary slightly with $N_{s}$, a linear dependence is assumed as follows:

$$
\begin{aligned}
280 a_{1}+a_{0} & =-0.126 \\
360 a_{1}+a_{0} & =-0.142 \\
a_{0} & =-0.07, a_{1}=-0.0002 \\
b_{1} / 280+b_{0} & =-0.0013 \\
b_{1} / 360+b_{0} & =-0.0006 \\
b_{0} & =-0.0017, b_{1}=-0.83 \\
c_{1} & =-0.07-0.0002 N_{s} \\
c_{2} & =-0.83+0.0017 N_{s}
\end{aligned}
$$

$a_{0}, a_{1}, b_{0}$, and $b_{1}$ are regression coefficients

$$
\begin{aligned}
\Delta R_{e h}=\Delta R_{e o} \exp - & {\left[\left(0.0002 N_{S}+0.070\right) h\right.} \\
& \left.+\left(\frac{0.83}{N_{S}}-0.0017\right) h^{2}\right]
\end{aligned}
$$

where $h$ is in kilometers. 


\section{ACKNOWLEDGMENT}

The author would like to thank Dr. G. H. Millman for his generosity in sharing available range-error correction data. He would also like to thank Dr. J. Studenny of Canadian Marconi Company, Quebec, Canada, and B. Weijers of Air Force Research Lab, Hanscom AFB, MA, for their helpful discussions.

\section{REFERENCES}

[1] E. E. Altshuler, "Corrections for tropospheric range error," AFCRL-710419, July 1971.

[2] E. E. Altshuler and P. M. Kalaghan, "Troposheric range error corrections for the NAVSTAR system," AFCRL-TR-74-0198, Apr. 1974

[3] J. C. Schelleng, C. R. Burrows, and E. B. Ferrell, "Ultrashort-wave propagation," Proc. IRE, vol. 21, pp. 427-463, 1933.

[4] B. R. Bean and E. J. Dutton, Radio Meteorology. New York: Dover, 1966.

[5] Rocket Panel, "Pressures, densities, and temperatures in the upper atmosphere," Phys. Rev., vol. 88, pp. 1027-103, 1952.

[6] "ARDC model atmosphere 1956," in Handbook of Geophysics for Air Force Designers, AFCRC, ARDC, USAF, 1957.

[7] M. Dubin, "Index of refraction above 20000 feet," J. Geophys. Res., vol. 59, pp. 339-344, 1954

[8] H. S. Hopfield, "Two-quartic tropospheric refractivity profile for correcting satellite data," J. Geophys. Res., vol. 74, pp. 4487-4499, 1969.

[9] _ "Tropospheric effect on electromagnetically measured range: Prediction from surface weather data," Radio Sci., vol. 6, no. 3, pp 357-367, 1971.

[10] B. W. Parkinson and J. J. Spilker, "Global positioning system: Theory and applications," Progress Astronaut. Aeronaut., vol. 1, ch. 13, pp. 517-546, 1996.

[11] B. R. Bean, B. A. Cahoon, and G. D. Thayer, "CRPL standard atmospheric radio refractive index sample NBS," Tech. Note 44, 1960.

[12] K. A. Norton, "Effects of tropospheric refraction in earth-space links," in Proc. 2nd Troposph. Refraction Effects Tech. Rev. Meet., Electron. Syst. Div., Bedford, MA, Nov. 1964, vol. TDR-6 L-103, pp. 155-193.
[13] G. H. Millman, "Tropospheric effects on space communications," in AGARD Conf. Proc. 70 Troposph. Radio Wave Propagat., Düsseldorf, Germany, Sept. 1970, vol. AGARD CP-7071, p. 4.

[14] _ "Atmospheric and extraterrestrial effects on radio wave propagation," G.E. TIS RGIEMH 29, 1961.

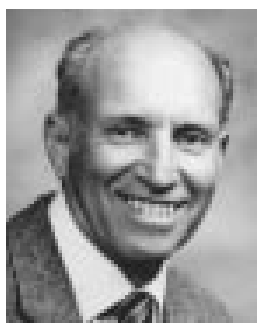

Edward E. Altshuler (S'54-M'55-SM'62-F'84 LF'95) received the B.S. degree in physics from Northeastern University, Boston, MA, in 1953, the M.S. degree in physics from Tufts University, Medford, MA, in 1954, and the Ph.D. degree in applied physics from Harvard University, Cambridge, MA, in 1960 .

Before joining Air Force Cambridge Research Labs (AFCRL), Hanscom AFB, MA in 1960, he was employed by Arthur D. Little and Massachusetts Institute of Technology, Cambridge, and Sylvania Electric, Waltham, MA. He left AFCRL in 1961 to become Director of Engineering at Gabriel Electronics, Millis, MA, but later returned to AFCRL in 1963 as Chief of the Propagation Branch from 1963 to 1982. He was a Lecturer in the Northeastern University Graduate School of Engineering from 1964 to 1991. He is currently conducting antenna research for the Air Force Research Laboratory at Hanscom Air Force Base, MA. He was Associate Editor of Radio Science from 1976 to 1978 and has over 100 scientific publications, patents, and presentations.

Dr. Altshuler was Chairman of the IEEE Boston Section Antennas and Propagation Society from 1965 to 1966 and served as Chairman of the 1968 IEEE AP-S/URSI Symposium in Boston. He was Chairman of the IEEE Boston Section Fellows and Awards Committee from 1993 to 1994 and Chairman of the IEEE Boston Section from 1995 to 1996. He also serves on the Antennas and Propagation Society Awards Committee and is a member of Comissions B and F of the International Radio Scientific Union. He has served on the Air Force Scientific Advisory Board, was Chairman of the NATO Research Study Group on Millimeter Wave Propagation and Target/Background Signatures from 1974 to 1993, and was President of the Hanscom Chapter of Sigma Xi from 1989 to 1990. He received the IEEE Harry Diamond Memorial Award in 1997. 